Virtual Mentor. February 2003, Volume 5, Number 2.

doi: 10.1001/virtualmentor.2003.5.2.jdsc1-0302

Journal Discussion

\title{
ER Physicians and Police Collaboration
}

\section{Some public health officials argue that if emergency physicians report violent crimes to local police, there will be a decrease in community violence.}

\section{Swathi Arekapudi}

The first stop for most victims of violence is their local emergency room. Of the 37 million visitors to emergency rooms in the United States in 1999, 7 percent had injuries related to intentional violence [1]. Certain kinds of violent acts, such as child abuse and dog bites must be reported to police in the US; in some states, physicians are required to report domestic violence and alcohol-related car accidents [1,2]. Not all violent acts must be reported by emergency room personnel, however, and the police are often not notified.

In "Emergency Medicine and Police Collaboration to Prevent Community Violence," Jonathan Shepherd argues that much more could be done to stem violence in the community through a health services-criminal justice system collaboration [3]. Sheperd reasons that a stronger relationship between emergency room physicians and the police will lead to more investigations and, as a result, more convictions. Such an increase in investigations and convictions will act as a deterrent and lead to less community violence. There is some evidence that punishment deters future crime, including studies comparing the likelihood of conviction and the levels of violence between the United Kingdom and the US. One study Shepherd cites showed that an inverse correlation exists between the likelihood of conviction and the level of violence [4].

Shepherd suggests that emergency room physicians can decrease community violence by facilitating increased rates of police reporting by, or on behalf of, the injured. In situations where the victim does not want to have the police involved, non-confidential material (such as where, when, and how the injury was inflicted) could be collected, aggregated, and distributed to the police. Such a process could yield information on previously unknown kinds of violence or provide specific locations where certain forms of violence are concentrated. This strategy has proved successful in some instances. Shepherd points out that the most frequently used weapon in the UK, bar glassware, was first identified from such information. Because of this data, glassware in the UK is now formed from toughened glass that reduces the risk of injury.

Epidemiologists studying criminal law have shown that laws can be effective means of addressing public health problems, such as violence. Shepherd points to a study that links laws requiring guns to be put in locked containers to fewer accidental shooting deaths in children [5]. In the emergency room, reporting of violence would benefit the health of the community as well as the individual patient. Since half of all assault victims in the ER have been assaulted before, and most violent offenses are committed by a small proportion of offenders, intervening early would prevent much harm. In a Philadelphia study, 6 percent of chronic offenders accounted for 69 percent of all aggravated assaults, 71 percent of homicides, 73 percent of forcible rapes, and 82 percent of robberies [6].

Shepherd argues that there are 4 types of barriers to reporting intentional violence in the emergency room: attitudinal, logistic, ethical, and legal. An attitudinal barrier is the position that violence prevention should not be the responsibility of medical professionals because this would allow the police force to divert some of the blame of the presence of crime to the medical establishment. There are additional worries that such collaboration indicates an "unacceptable medical paternalism" [6]. Understandably, fewer attitudinal objections have been found among police. 
Instead, much of their concern stems from the fact that violence is not reported to them. Logistic barriers include the lack of facilities for patient reporting, an inability to record the circumstances of violence, poor communication with the police, and "the often exclusively health agenda" of emergency

rooms [7].

A study carried out in 5 emergency rooms in the UK illustrated ethical objections to increased reporting. Physicians opposed increased partnership with law enforcement for reasons of "patient confidentiality, maintaining a neutral stance in relation to issues of blame, and protecting the patient" (in decreasing order of importance). Reasons given for wanting to report violence were reducing risk to others, the severity of violent injuries, the use of weapons, and the vulnerability of the injured [6].

There are potential benefits to increased collaboration between emergency departments and the police but also significant problems, many of which Shepherd sees more as obstacles to be overcome, such as the medicalization of violence and the effect such a position would have on the patient-physician relationship. Though the patient-physician relationship is different in the emergency room, physician reporting to the police will cause patients to distrust the health care system (especially if they are the perpetrators of violence) and perhaps fewer patients would go to the emergency room. California physicians who were surveyed expressed a strong aversion to such collaboration. If such mandatory reporting of abuse were instated, 64 percent of primary care physicians and 25 percent of ER physicians who responded would not comply because of concerns for patient safety, patient confidentiality, patient autonomy, and the integrity of the patient-physician relationship [8].

Health care can be perceived as both a good in itself and as a gateway to other ends, in this case, the prevention of violence. A balance between the needs of the individual and those of the community allows medicine to serve its dual role, but where this balance lies is difficult to resolve. Shepherd leans towards a plan that places greater weight on the needs of the community than on confidentiality of patient information. Wherever one believes this balancing point lies, whether favoring individual or community needs, that position will present difficulties and demand a defense.

\section{Questions for Discussion}

1. It is often noted that the patient-physician relationship is, at best, "attenuated" in emergency room encounters where, often, patient and physician are meeting for the first time. When does a patient-physician relationship start? Does the minimal relationship between patient and physician in the emergency room give the physician greater freedom to share patient information with police officers, even against the wishes of his or her patient?

2. How does the physician's role on behalf of public health differ from a police officer's role in the name of public protection?

3. Should physicians share accountability for community violence?

4. If a Shepherd-like plan were instated in an emergency department, how might that affect whether or not certain kinds of victims (such as those of domestic abuse, or those who are already on slippery legal footing) receive medical treatment?

\section{References}

1. Hargarten SW. Docs and cops: a collaborating or colliding partnership? Ann Emer Med. 2001;38:438-440. View Article PubMed Google Scholar

2. Cole TB. What can we do about violence? JAMA. 1999;282:481-483. View Article PubMed Google Scholar

3. Shepherd JP. Emergency medicine and police collaboration to prevent community violence. Ann Emer Med. 2001;38:430-437.

View Article PubMed Google Scholar

4. Shepherd, 432.

5. Cummings P, Grossman DC, Rivara FP, et al. State gun storage laws and childhood mortality due to firearms. 
JAMA. 1997;278:1084-1086.

View Article Google Scholar

6. Shepherd, 433.

7. Shepherd, 434

8. Cole, 482.

The viewpoints expressed on this site are those of the authors and do not necessarily reflect the views and policies of the AMA.

(C) 2003 American Medical Association. All Rights Reserved. 